\title{
TRANS-PTEROSTILBENE AND ITS DERIVATIVE 2,4-DIMETHOXY-6 -HYDROXYPHENANTHRENE IN THE LEAVES OF PARTHENOCISSUS TRICUSPIDATA
}

\author{
NADĚŽDA VRCHOTOVÁ and JAN TříSKA* \\ Global Change Research Institute, Czech Academy of Sciences, Bělidla 4a, 60300 Brno, Czech Republic \\ * Corresponding author: triska.j@czechglobe.cz
}

\section{ABSTRACT}

Trans-pterostilbene, cis-pterostilbene and 2,4-dimethoxy-6-hydroxyphenanthrene were detected in the leaves of Parthenocissus tricuspidata (Siebold et Zuccarini) Planchon. It was recorded for this plant for the first time that in autumn, when the leaves change in colour, there is an increase in content of 2,4-dimethoxy-6-hydroxyphenanthrene (DMPH), which is a derivative of trans-pterostilbene.

Keywords: Parthenocissus tricuspidata, trans-pterostilbene, 2,4-dimethoxy-6-hydroxyphenanthrene, trans-resveratrol

\section{Introduction}

Parthenocissus tricuspidata (Siebold et Zuccarini) Planchon, known as Japanese creeper, Boston ivy, Grape ivy or Japanese ivy, belongs to the family Vitaceae. It is native to eastern Asia.

The attention here is mainly on the detection and content of stilbenes, because they are known to be biologically active substances. In stem wood, in addition to trans-resveratrol and trans-piceid (Jeon et al. 2013), trans- $\varepsilon$-viniferin, pallidol, ampelopsin $\mathrm{F}$, isoampelopsin $\mathrm{F}$ (Tanaka et al. 1998), parthenostilben A, parthenostilben B (Kim et al. 2005) and tricuspidatol A (Lins et al. 1991) are reported. In the leaves trans-piceid (Son et al. 2007; Park et al. 2008), longistylin A and longistylin B (Son et al. 2007) and trans-piceatannol (Kundaković et al. 2008) are reported.

The main goal of this study was to analyse the biologically active compounds present during the senescence of Parthenocissus tricuspidata leaves with the focus on trans-pterostilbene and its transformation products.

\section{Materials and Methods}

\section{Plants material and preparation of extracts}

The leaves of Parthenocissus tricuspidata (Siebold et Zuccarini) Planchon were collected at different locations in the Czech Republic in the years 2012-2014 (Table 1). The samples of leaves were frozen at $-18^{\circ} \mathrm{C}$ and then lyophilized. Finely ground samples were extracted with ethyl acetate for $40 \mathrm{~min}$ at $50^{\circ} \mathrm{C}$ and the sediment was washed twice with ethyl acetate. Supernatants were pooled, ethyl acetate was evaporated in a stream of nitrogen and then the samples were diluted in methanol. The subsamples from each sample used in the analysis were prepared in triplicate.
Table 1 Localities and data sampling.

\begin{tabular}{|l|l|r|l|}
\hline \multicolumn{2}{|c|}{ Locality } & \multicolumn{1}{c|}{$\begin{array}{c}\text { Data of } \\
\text { collection }\end{array}$} & \multicolumn{1}{c|}{ Leaf colour } \\
\hline A & $\begin{array}{l}\text { Kutná Hora } \\
49^{\circ} 56^{\prime} 54^{\prime \prime} \mathrm{N} 15^{\circ} 16^{\prime} 6^{\prime \prime} \mathrm{E}\end{array}$ & 20.9 .2012 & green; yellow-dark red \\
\hline B & $\begin{array}{l}\text { Hluboká nad Vltavou } \\
49^{\circ} 3^{\prime} 8^{\prime \prime} \mathrm{N} 14^{\circ} 26^{\prime} 3^{\prime \prime} \mathrm{E}\end{array}$ & 9.10 .2013 & $\begin{array}{l}\text { green; red; dark-red; } \\
\text { yellow-green-dark-red; } \\
\text { yellow-red }\end{array}$ \\
\hline C & $\begin{array}{l}\text { Lednice } \\
48^{\circ} 47^{\prime} 60^{\prime \prime} \mathrm{N} 16^{\circ} 48^{\prime} 12^{\prime \prime} \mathrm{E}\end{array}$ & $\begin{array}{r}10.10 .2013 \\
17.10 .2014\end{array}$ & $\begin{array}{l}\text { green; green-dark red; } \\
\text { green-yellow red }\end{array}$ \\
\hline D & $\begin{array}{l}\text { Starý Smolivec } \\
49^{\circ} 31^{\prime} 39^{\prime \prime} \mathrm{N} 13^{\circ} 45^{\prime} 7^{\prime \prime} \mathrm{E}\end{array}$ & $\begin{array}{r}18.8 .2013 \\
16.9 .2013\end{array}$ & $\begin{array}{l}\text { green; green-red border; } \\
\text { green-dark red; red }\end{array}$ \\
\hline
\end{tabular}

\section{Liquid chromatography}

The extracts were analyzed using a HPLC (HP 1050 Ti-series, Hewlett Packard Palo Alto, CA, USA) and a Luna C18(2) column, $150 \mathrm{~mm} \times 2 \mathrm{~mm}, 3 \mu \mathrm{m}$ (Phenomenex, Torrance, CA, USA), G1315B diode array detector (DAD, Agilent) and G1321A fluorescence detector (FLD, Agilent). The compounds were identified by measurements made using a LC-MS (LCQ Accela Fleet (Thermo Fisher Scientific, San Jose, CA, USA). Separations using HPLC and LC-MS (APCI) are described in detail in Tŕíska et al. (2012).

As standards trans-resveratrol and 9-phenanthrol from Sigma-Aldrich were used and trans-pterostilbene was kindly provided by prof. Jan Šmidrkal, University of Chemistry and Technology, Prague. Acetonitrile and methanol were from Merck, $o$-phosphoric acid and formic acid from Sigma-Aldrich.

\section{Data analysis}

Quantification of trans- and cis-pterostilbene using HPLC was done using a calibration curve for trans-pterostilbene (diode array detector, at $315 \mathrm{~nm}$ ); quantification of trans-resveratrol using a calibration curve for trans-resveratrol (diode array detector, at $315 \mathrm{~nm}$ ); that of 2,4-dime- 
thoxy-6-hydroxyphenanthrene using a calibration curve for 9-phenanthrol (synonym for 9-hydroxyphenanthrene) using a fluorescence detector (Ex $315 \mathrm{~nm}$, Em $395 \mathrm{~nm}$ ). LOD and LOQ for trans-resveratrol were $0.055 \mu \mathrm{g} / \mathrm{ml}$ and $0.184 \mu \mathrm{g} / \mathrm{ml}$,respectively,fortrans-pterostilbene, $0.042 \mu \mathrm{g} / \mathrm{ml}$ and $0.142 \mu \mathrm{g} / \mathrm{ml}$, for 9-phenanthrol $0.042 \mu \mathrm{g} / \mathrm{ml}$ and $0.141 \mu \mathrm{g} / \mathrm{ml}$. Each value was based on three measurements.

\section{Results and Discussion}

The samples were collected from four locations in autumn, when the leaves had begun to change in colour from green to yellow and red. The samples from one of these locations were collected on three dates in one year, the samples from the second location were collected in two consecutive years. The locations and dates of sampling are shown in Table 1.

In the samples trans-resveratrol, trans-pterostilbene and 2,4-dimethoxy-6-hydroxyphenanthrene (DMPH) were identified. It was possible to detect also cis-pterostilbene in some samples. The irradiated trans-pterostilbene standard served as a test substance to identify compounds present in the extracts.

By irradiating the methanol solution of trans-pterostilbene at $254 \mathrm{~nm}$ for 20 hours, a mixture of trans-pterostilbene, DMPH and cis-pterostilbene was obtained. The structures of these substances are shown in Fig. 1 and their DAD spectra in Fig. 2. The samples were also measured using LC-MS (APCI in positive mode): we recorded for 2,4-dimethoxy-6-hydroxyphenanthrene molecular ion at $m / z 255[\mathrm{M}+\mathrm{H}]^{+}$and for trans-pterostilbene and cis-pterostilbene molecular ion at $\mathrm{m} / z 257[\mathrm{M}+\mathrm{H}]^{+}$.

The content of DMPH and the stilbenes studied is very variable, but the DMPH content was always much greater in autumn "coloured leaves" compared to green leaves. The highest content of DMPH was in the samples of leaves that were either completely or partially dark red (Figs 3-6). The highest content of DMPH was recorded in the leaves from site A in 2012 and from site C in 2013. The amount of trans-pterostilbene was only a few $\mathrm{mg} / \mathrm{kg}$; for many samples, the content of trans-pterostilbene was below the detection limit (e.g. in the green leaves from localities A, B and D). Only traces of cis-pterostilbene were detected in three samples: Locality A - yellow-dark red leaves, locality B - red leaves, locality $\mathrm{C}$ - green-dark red leaves 10.10.2013. In the green leaves from site $C$ in 2014 the content of both stilbenes was below the detection limit.

Derivatives of phenanthrene are very common biologically active compounds in the plant kingdom (Kovács et al. 2008), but to our knowledge there is no information on the presence of DMPH in plants. Only the dihydro derivative of DMPH (double bond saturated in the positions 9,10$)$ is mentioned in the literature under the name orchinol (Kovács et al. 2008). DMPH was patented (Hashimoto et al. 1976) as a novel growth modifier useful<smiles>COc1cc(/C=C\c2ccc(O)cc2)cc(OC)c1</smiles>

cis-pterostilbene

trans-pterostilbene

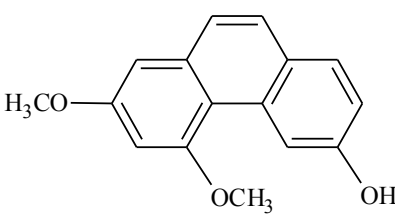

2,4-dimethoxy-6-hydroxyphenanthrene (DMPH)

Fig. 1 The structure of analysed compounds.

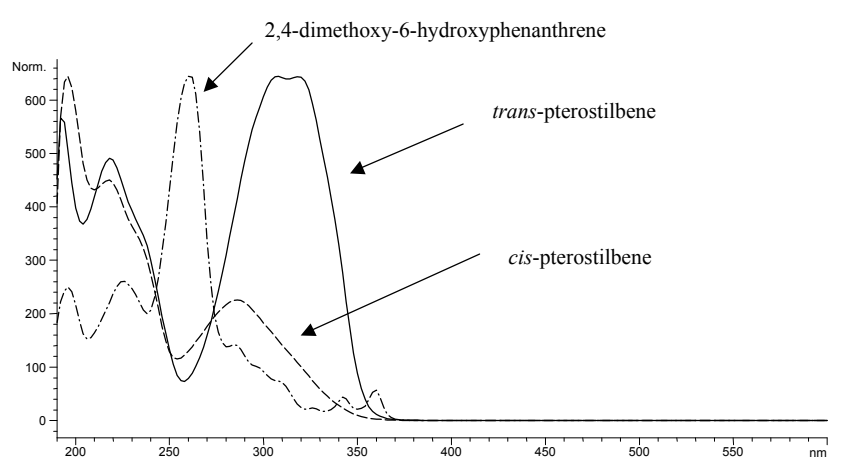

Fig. 2 DAD spectra of trans-pterostilbene and its derivatives.

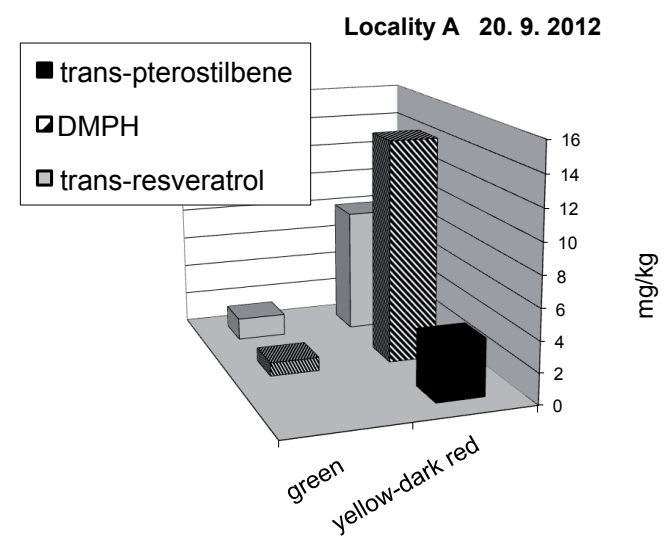

Fig. 3 The content of trans-resveratrol, trans-pterostilbene and DMPH in the leaves on the locality A.

for controlling growth, germination of seeds and regulating the dormant stages of seeds, bulbs and buds.

Formation of phenanthrene derivatives as final products in the UV photo isomerization of trans-resveratrol to cis-resveratrol and final cyclization to the derivative phenanthrene in the leaves of Vitis vinifera plants following attack by Plasmopara viticola is described in the literature (Tríska et al. 2012). Senescence of Parthenocissus tricuspidata leaves, visibly manifested by the colour change in autumn, may have a similar mechanism also 
Locality B 9. 10. 2013

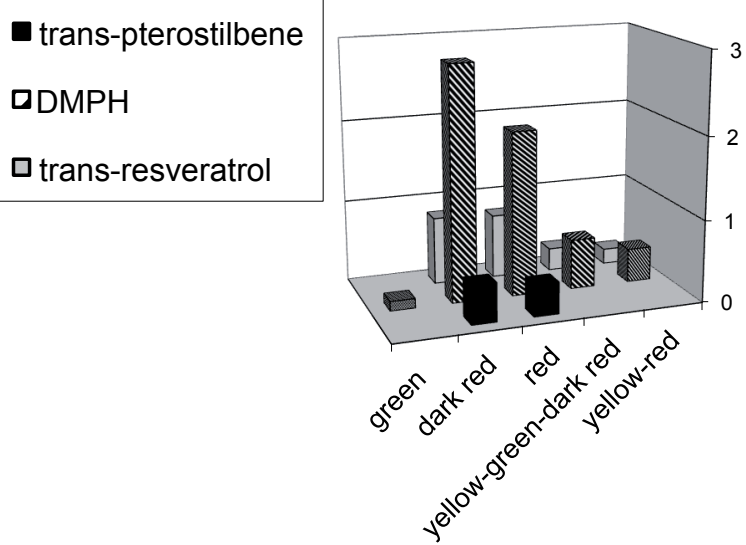

Fig. 4 The content of trans-resveratrol, trans-pterostilbene and DMPH in the leaves on the locality B.

Locality D 2013

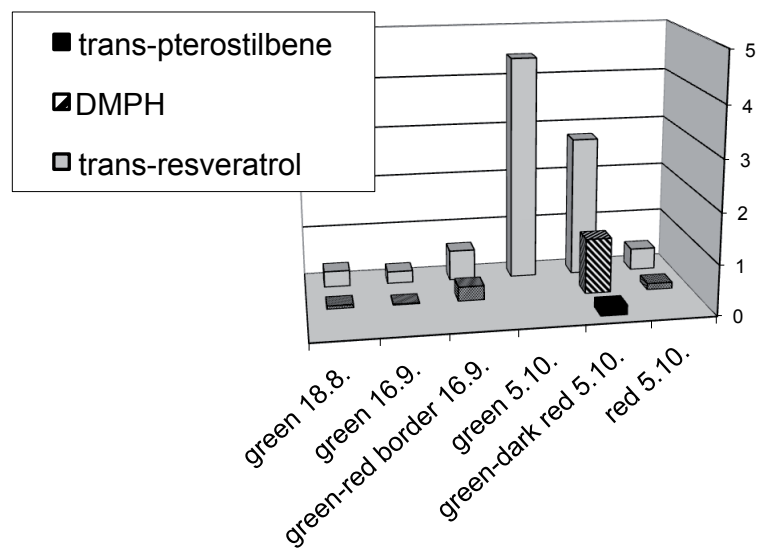

Fig. 6 The content of trans-resveratrol, trans-pterostilbene and DMPH in the leaves on the locality $D$.

ending with phenanthrene derivative, in this case mainly with DMPH.

\section{Conclusions}

During the senescence of the leaves of Parthenocissus tricuspidata, visibly manifested in autumn by the change in their colour, trans-pterostilbene, originally present in the leaves, is tranformed into 2,4-dimethoxy-6-hydroxyphenanthrene, which is reported here for the first time in the leaves of Parthenocissus tricuspidata.

\section{Acknowledgements}

This work was supported by the Ministry of Education, Youth and Sports of the Czech Republic within the National Sustainability Program I (NPU I), grant no.
Locality C $2013+2014$

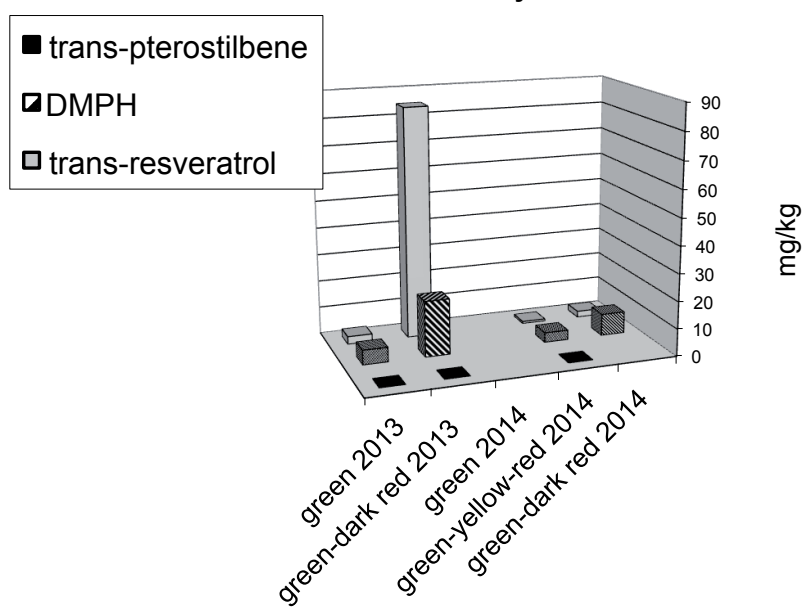

Fig. 5 The content of trans-resveratrol, trans-pterostilbene and DMPH in the leaves on the locality $C$.

LO1415. We also wish to thank I. Soural and K. Matějková for assistance in collecting plant material and thank J. Šmidrkal for providing trans-pterostilbene.

\section{REFERENCES}

Hashimoto T, Kawaraga A, Tamura S (1976) Plant growth modifier and a process for preparation thereof. United States Patent 3971651.

Jeon J-S, Kim CY (2013) Preparative separation and purification of flavonoids and stilbenoids from Parthenocissus tricuspidata stems by dual-mode centrifugal partition chromatography. Sep Purif Technol 105: 1-7.

Kim HJ, Saleem M, Seo SH, Jin C, Lee YS (2005) The new antioxidant stilbene dimers, parthenostilbenins A and B from Parthenocissus tricuspidata. Planta Med 71: 973-976.

Kovács A, Vasas A, Hohmann J (2008) Natural phenanthrenes and their biological activity. Phytochemistry 69: 1084-1110.

Kundaković T, Stanojković T, Milenković M, Grubin J, Juranić Z, Stevanović, Kovačević N (2008) Cytotoxic, antioxidant, and antimicrobial activities of Ampelopsis brevipendunculata and Parthenocissus tricuspidata (Vitaceae). Arch Biol Sci 60: 641-647.

Lins AP, Felicio D’arc J, Braggio MM, Roque LC (1991) A resveratrol dimer from Parthenocissus tricuspidata 30: 3144-3146.

Park W-H, Lee S-J, Moon H-I (2008) Antimalaric activity of a new stilbene glycoside from Parthenocissus tricuspidata in mice. Antimicrob Agents Chemother 52: 3451-3453.

Son IH, Chung I-M, Lee S-J, Moon H-I (2007) Antiplasmodial activity of novel stilbene derivatives isolated from Parthenocissus tricuspidata from South Korea. Parasitol Res 101: 237-241.

Tanaka T, Ohyama M, Morimoto K, Asai F, Iinuma M (1998) A resveratrol dimer from Parthenocissus tricuspidata. Phytochem 48: 1241-1243.

Tříska J, Vrchotová N, Olejníčková J, Jílek R, Sotolář R (2012) Separation and identification of highly fluorescent compounds derived from trans-resveratrol in the leaves of Vitis vinifera infected by Plasmopara viticola. Molecules 17: 2773-2783. 